\title{
Examining Distance Learners in Hybrid Synchronous Instruction: Successes and Challenges
}

\author{
Enilda Romero-Hall \\ University of Tampa \\ Cristiane Vicentini \\ University of Miami
}

\begin{abstract}
This paper reports on a case study investigating distance learners participating in graduate-level hybrid synchronous instruction. This research helps inform the design of hybrid synchronous instruction in which face-to-face and distance learners engage in class sessions. Data were collected using electronic journals, individual interviews, and a focus group. The results of the data analysis provide evidence that in this case, hybrid synchronous instruction improved the study habits of distance learners. On the other hand, the case study results also revealed that there are challenging pedogogical aspects which the distance learners had to overcome during hybrid synchronous instruction. Among such challenges were the interactions, relationships, and communication exchanges between distance learners, their face-to-face counterparts, and the instructor.
\end{abstract}

Keywords: Hybrid instruction; synchronous instruction; distance learning; case study

Romero-Hall, E. \& Vicentini, C. (2017). Examining distance learners in hybrid synchronous instruction: Successes and challenges. Online Learning, 21(4), 141-157. doi: 10.24059/olj.v21i4.1258

\section{Examining Distance Learners in Hybrid Synchronous Instruction: Successes and Challenges}

Higher education institutions need to explore innovative learning environments without necessarily increasing space on campus (Oyarzun \& Martin, 2013). A novel learning environment that is now very popular in higher education is the implementation of asynchronous online instruction (Lee \& Dashew, 2011; McGee \& Reis, 2012). A strong utilitarian argument for asynchronous online instruction is that it provides the opportunity to teach new groups of students in places around the world (Popov, 2009). However, asynchronous online instruction can be lonely and disengaging for learners that enjoy social interactions, immediate feedback, and interactive class sessions (Cunningham, 2014; Lee \& Dashew, 2011). A good middle ground that could help 
increase the number of students enrolled in a traditional class but not require additional physical classroom space is the implementation of hybrid synchronous instruction (Bonakdarian, Whittaker, \& Yang, 2010; Butz, Stupnisky, Peterson, \& Majerus, 2014; Niemiec \& Otte, 2009; Stewart, Harlow, \& DeBacco, 2011). This type of instruction does not present the challenges of asynchronous online education, and can be of great benefit for many contemporary students seeking to advance their education but are bound by work, family, or geography.

Hybrid synchronous instruction is also referred to as blended synchronous learning (Hastie, Hung, Chen, \& Kinshuk, 2010), synchronous online teaching (Park \& Bonk, 2007), or synchronous hybrid delivery (Butz et al., 2014). This type of delivery is important because it is anticipated that universities will have inadequate physical facilities to meet the demands of an increasing student population. There has been a surge in the number of students graduating high school and enrolling in college; in 2022 that number is estimated to be 3.4 million (White, Ramirez, Smith, \& Plonowski, 2010). In addition, college enrollment rose 23 percent between 1995 and 2005 (White et al., 2010). This trend is expected to continue over the next ten years, leaving universities with a lack of brick and mortar space to meet the needs of instruction. The aim of this paper is to understand the effectiveness and efficiency of hybrid synchronous instruction from the perspective of distance learners engaged in graduate-level coursework.

\section{Review of Related Literature}

Universities need to prepare to deliver courses in alternative ways to ensure the continuity of instruction for adult learners and non-traditional students (Bower, Dalgarno, Kennedy, Lee, \& Kenney, 2015; Butz et al., 2014; Stewart et al., 2011). Many non-traditional students, as well as working adults seeking to improve their professional opportunities, recognize the need for additional education to accomplish their goals (Bonakdarian et al., 2010; McGee \& Reis, 2012). A number of these potential students often find themselves under time constraints to pursue this endeavor. Therefore, such students opt for online classes as they offer greater flexibility in terms of both scheduling and location (Butz et al., 2014). The traditional notion of the on-campus university experience is changing, with many students choosing to participate wholly or partially away from their institutions' campuses.

Sadly, most programs that are moved to an online asynchronous format predominantly suffer from a loss of social interactions, which results in students' feelings of isolation (Chakraborty \& Victor, 2004; Oyarzun \& Martin, 2013). The learners miss the benefits that come from the more traditional face-to-face environment, such as closer contact and engagement with the instructor and fellow students and the immediate feedback that can result from this setting (Bonakdarian et al., 2010; Chakraborty \& Victor, 2004; Stewart et al., 2011). Additionally, in some cases, these asynchronous methods may not provide effective support for learning in cases where students need to engage in real-time conversations, share audio/visual content, or where a sense of presence and community are important elements of the learning episode (Bower, Kenney, Dalgarno, Lee, \& Kennedy, 2013; Stewart et al., 2011).

In this context, hybrid synchronous instruction could potentially allow students to retain many of the benefits of online instruction while simultaneously gaining some of the advantages of face-to-face classes, resulting in effective, efficient, and engaging learning (Bell, Sawaya, \& Cain, 2014; Bonakdarian et al., 2010; Bower et al., 2015; Stewart et al., 2011). Researchers believe that this approach holds much promise as an alternative that offers the "best of both worlds" for 
students unable to attend traditional face-to-face classes but who are also reluctant to commit to the purely online classroom format (Bonakdarian et al., 2010). Learning design using media-rich real-time communication tools such as video conferencing and/or web conferencing have become increasingly popular (Bell et al., 2014; Bower et al., 2013). These technologies can be used to facilitate efficient discussion, content exchange, education international collaborations, and identity representation (Hastie et al., 2010; Popov, 2009).

\section{Prior Research}

Although there has been a significant number of implementation cases (Bell et al., 2014; Bower et al., 2013; Butz et al., 2014; Chakraborty \& Victor, 2004; Oyarzun \& Martin, 2013; Park \& Bonk, 2007; Popov, 2009; Roseth, Akcaoglu, \& Zellner, 2013; Stewart et al., 2011; Szeto, 2015), only a small number of studies have investigated the learning experience of the distance students enrolled in a hybrid synchronous course. White et al. (2010) examined the feasibility of delivering a course on-campus and in real-time, simultaneously transmitting it to students who were remotely accessing the same course. The results of the investigation showed that all students taking the course at a distance indicated that it was a good learning experience. Participants reported that the presentation slides were effective, the web conferencing tool was easy to use, the technical support received was sufficient, and the ability to review the videos after class was appreciated. The participants did report and comment on some technology problems experienced during the live sessions and how these may have prevented them from fully engaging in classroom discussion or activities due to the discontinuation of the live stream. Nevertheless, overall, participants indicated that it felt as if they were in the classroom when all the technology was working correctly.

Similarly, Bonakdarian et al. (2010) pilot-tested and evaluated the implementation of a hybrid synchronous course following the $\mathrm{e}^{3}$-learning framework, which specified that e-learning should provide an effective, efficient, and engaging environment. The results of the implementation confirmed the assumption that indeed the hybrid synchronous course provided a more efficient and engaging learning environment for the students, when compared to a purely face-to-face or online course. The online students overwhelmingly appreciated the synchronous, instructor-led interactions, and live demonstrations. However, the students indicated that the video feed of the classroom and interactions with other students were ineffective (primarily due to the technology issues).

A study conducted by Cunningham (2014) asked distance learners and on-campus learners who had participated in a hybrid synchronous classroom to anonymously evaluate the experience of having physical and virtual participants sharing a physical space. Eleven students shared their experience. The results indicate that the distance learners did not feel welcomed by the on-campus learners. Additionally, on-campus learners felt some resentment of the time and effort taken to assist the distance learners when technical issues occurred. There was also some frustration caused by the lack of perception of social cues by the distance learners, due to the limitations in their mode of participation, as both groups of learners mentioned the challenges with sound quality. Overall, both groups of learners reported seeing the other group as separate from themselves.

Another study that focused on the learning experience of distance learners was conducted by Rogers, Graham, Rasmussen, Campbell, and Ure (2003). As part of a case study, Rogers et al. (2003) surveyed and conducted semi-structured interviews with seven distance learners participating in hybrid synchronous instruction. The results of the survey and the interviews 
revealed that the distance learners were very grateful for the ability to participate in class and receive a graduate degree, even though they could not physically travel to campus. One of the main issues mentioned was the social interaction with the on-campus learners and the instructors. Several distance learners mentioned that there were some negative aspects due to technology limitations, for example, the lag time or delay of voice messages to the physical classroom. The distance learners also mentioned positive aspects related to the social interaction during hybrid synchronous instruction. For example, they enjoyed the ability to see each other using video and to converse using the chat features of the video conferencing software.

Overall, due to its newness, research on hybrid synchronous instruction focusing on the distance learners' experience has not been fully explored. As a result, the efficacy and efficiency of hybrid synchronous instruction needs further investigation to satisfactorily demonstrate how this mode of instruction impacts distance learners, what pedagogical strategies are best suited for these learners, and what the best ways are to provide support for them.

\section{Purpose Statement and Research Question}

This case study investigates and describes the learning experience of distance learners participating in graduate-level education classes through hybrid synchronous instruction. The purpose of this research is to understand the effectiveness and efficiency of hybrid synchronous instruction from the perspective of the distance learners. This research helps inform the instructional design of hybrid synchronous instruction in which face-to-face and distance learners engage during synchronous class sessions. This investigation was designed to render valuable data for instructors and institutions that are currently engaged or are considering engaging in hybrid synchronous instruction. The research question addressed in this investigation was the following: What are the challenges and successes of distance learners engaged in hybrid synchronous instruction?

\section{Operationalized Variables}

Face-to-Face Learners: Students in the traditional educational environment in which classes take place at a specific time and place in the university campus.

Distance Learners: Students located in other cities and/or states within the country, taking classes at a distance in the hybrid mode of instruction, where they join class meetings using video conferencing technology.

\section{Methods}

\section{Research Paradigm}

The approach used for this qualitative investigation was a case study; in other words, a strategy of inquiry in which the researcher goes in-depth to explore a program, event, activity, process, or one or more individuals - elements of a bounded system (J. W. Creswell, 2009). Case studies are distinguished from other qualitative traditions because cases are researched in depth and the data are delineated by time period, activity, and place (Patton, 2015; Plummer, 2001). In case study investigations, researchers collect detailed information using a variety of data collection procedures over a sustained period of time (J. W. Creswell, 2009). Plummer (2001) described case studies as establishing "collective memories and imagined communities; and they tell of the concerns of their time and place." 
Case studies have long been used in the social sciences as a way to carefully document life stories and events (Patton, 2015; Yin, 2014). Case studies have emerged from the tradition of biographical writing within the fields of psychology, sociology, anthropology, political science, and history. They are particularly useful in counseling and education since practitioners are interested both in unique dimensions of a case (often a client or student), as well as their more generalized application to other individuals.

In this investigation, the case refers to the narratives of three individuals engaged in hybrid synchronous instruction while completing graduate level coursework. The case study method was used because it helped explain in an extensive and in-depth manner the challenges and successes of these distance learners engaged in a specific instructional model at a particular institution. Yin (2014) indicated that the distinctive need for case study research arises out of the desire to understand complex social phenomena. Therefore, a case study allows investigators to focus on a "case" and retain a holistic and real-world perspective.

\section{The Setting}

The participants of this investigation were enrolled in a master's degree program in a midsized private university. The university is located in the southeastern United States. Students enrolled in this program are of varied ages, backgrounds, and technical abilities. The program is primarily offered face-to-face but three students in the program were allowed to complete the remainder of the program as "distance learners" (see the "Participants" section). At the time of the implementation of these hybrid synchronous courses, no other programs had attempted to use technology to deliver synchronous online instruction.

The faculty evaluated various videoconferencing technologies and the best solution for the program was the adoption of Google Hangouts, along with the use of the Blackboard LMS, which offered asynchronous affordances for virtual classroom participation. Students were already familiar with the Google tools, since most students in the program have a Google+ account. The Google Hangouts video conferencing tool contained features such as real-time live application sharing, which captured the audio of the classroom dialogue and the instructor's lecture, as well as interactive capabilities for the distance learners, which provided them with access to students' comments and questions posed during class. Some of the interactive features included synchronous chat, the ability to ask questions in real-time via live audio, and the "step out" function, allowing the participant to leave the online classroom.

The program courses were all offered in the evening and were three hours in duration. On average, each course in the program had fifteen students enrolled per semester. Most courses were taught in a blended format, in which the class met every other week. The classrooms used for each of the courses attended by distance learners varied. Regrettably, the program did not have a designated classroom outfitted with web conferencing technology. However, all classrooms used by the faculty had a computer station with a computer that could be projected on to a screen.

Students in the courses offered in the program were not required to bring their laptops to the class meetings. Nonetheless, if they chose to bring their laptops to the classroom, they had access to wireless Internet and electric outlets to charge their laptops. During class meetings, students primarily attended face-to-face. In some rare instance, due to illness, work, or transportation issues, students attended the class meetings using video conferencing. Students have expressed positive feelings about their ability to choose. 
Since courses were developed for a face-to-face class, the professors were able to implement the same instructional strategies which would have been used if the classes were taught completely face-to-face. Because all instructors in the program were already comfortable with distance education tools and had experience teaching both face-to-face and distance education courses, the challenge to learn how to manage the new technologies did not pose a threat to instruction. In fact, the experience with distance education pedagogical tools assisted the professors in understanding how a hybrid synchronous course should be taught in this context. For the most part, the students at a distance were able to see the lecture slides that were used in the classroom. In some instances, the instructor would share the video image of the real-time class periods.

\section{Participants}

The participants in this case study investigation were three graduate students. These graduate students were specifically selected because they had started the master's program in a face-to-face format, but due to different circumstances, had to relocate to cities within the country (away from their academic institution). The participants, all of whom have received pseudonyms for anonymity, were all 18 years of age or older. Two of the students attended the program parttime, with a maximum of two courses per semester. One of the students was a full-time student, with a course load of three or four courses per semester.

Participants were enrolled in different courses in the graduate program. Before the students were allowed to participate at a distance, each instructor would contact the students and inform them how their participation in the course would occur throughout the semester. These included student requirements for training, computer hardware and software, attendance requirement, and specifications of how the in-class interactions/activities would be handled. It was important for the instructors to ensure that learning environments both face-to-face and online would remain equitable and as similar as possible.

Ryan: The Corporate Dad. One of the participants was an employee in a large corporation as well as a dedicated father to a young infant. Ryan started the program attending face-to-face classes on campus, but after a year in the program, he was offered a job in a different city (within the state) and accepted the offer to provide a better living standard to his family. Ryan attended the program at a distance for the remaining four semesters.

Katie: The Student and Mom. Another participant in this case study investigation was a full-time student in the program that had to relocate out of state because her husband was transferred due to his job. After attending the program at a distance for two semesters, Katie became a mom. She attended the program at a distance for the remaining four semesters.

Robin: The Full-Time Distance Student. The last participant in the case study was a fulltime student while attending the program on campus. After attending the program face-to-face for two semesters, Robin got engaged and relocated to her hometown. She attended the program at a distance for the remaining two semesters.

All of the partipants received an email invitation to take part in this research study from the principal investigator. The email provided the purpose of the research project, the risks and benefits of their participation, the IRB approval letter, and a PDF copy of the consent form. The participants were asked to reply "Yes, I agree to participate in this investigation" or "No, I am not interested in participating in this investigation." 


\section{Data Sources}

Data were collected during the last academic year in which the three graduate students were enrolled in the program. The researchers used various forms of data collection at different stages, including a one-hour individual interview via video conference with each of the distance learners at the end of the fall semester, a one-hour focus group session when all distance learners joined a video conference at the end of the spring semester, and voluntary electronic journal entries via Google Forms that could be completed throughout the academic year. The same protocol was used for both the individual interviews and the focus group (see Appendix A).

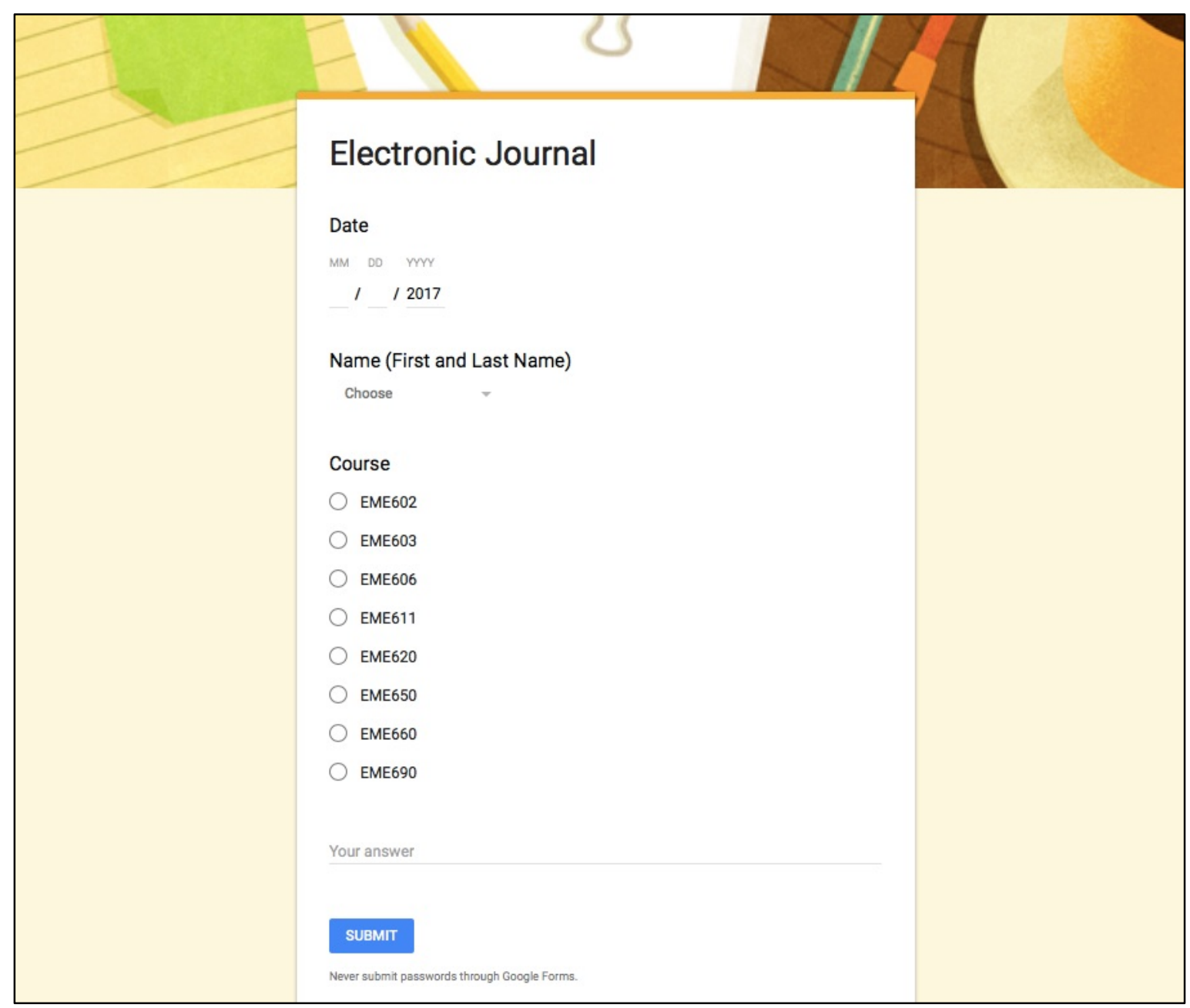

Figure 1. Electronic journal form.

The link to the electronic journal was sent to the participants via email. In the electronic journal, participants shared the date of the entry, their name, and their statements on feelings or experiences (see Fig. 1). Eleven journal entries were completed by the participants. These electronic journal entries were completed at will, whenever participants wanted to comment on their learning experiences throughout the academic year. 
A total of 7,270 words were analyzed. As recommended by J. W. Creswell (2009), an interim analysis was conducted, with an ongoing and iterative process until the case was fully explored. Each electronic journal entry, as well as transcripts from the individual interviews and the focus group were copied verbatim into an MS Word document. The next step was the reduction of the data (J. W. Creswell, 2009; Plummer, 2001). For this procedure, all journal entries, interviews, and focus group transcripts were coded. During the coding process, keywords and phrases were pulled from the data to develop initial codes (Yin, 2014). The researchers used Yin (2014) case study analysis recommendation in which code lists from both of the researchers were then compared against each other for possible similarities or discrepancies. Keywords and phrases were grouped into eighteen coding categories.

Following the reduction of the data, the horizontalization process (J. W. Creswell, 2009; Patton, 2015) occurred, with the purpose of spreading out the data and organizing it into meaningful clusters, in which irrelevant, repetitive, or overlapping data were eliminated. Ten main themes were identified from the horizontalization process. A spreadsheet was created to enter textual and structural descriptions for each of the main themes. To ensure the validity of this qualitative investigation and as advocated by J. Creswell (2009) and Patton (2015), data and investigator triangulations were part of the research process, since multiple data sources and investigators were used in the collection, analysis, and interpretation of the data.

\section{Results}

Ten themes emerged from the data collected. They will be described in turn.

\section{Connecting with Other Distance Learners}

One of the main themes that emerged in the data was related to the connections among other distance learners in the program. Participants expressed that they enjoyed the experience of being distance learners more when there were other classmates that were also at a distance. Having several distance learners in the same class allowed them to work in projects together and to connect with classmates that understood the challenges of being online. The participants found that if they worked together with other distance learners taking the same class, they were more active in the discussion of the class topics.

Having other distance learners in the same class also increased the social connection with other classmates, in addition to the intellectual interchange. As one participant (Ryan) mentioned, "There weren't any kind of social hurdles you had to cross over because you weren't in the room with them." Another participant (Katie) explained, "Having others at a distance with me, helped and created a sense of community. I had close connections with those because we bonded over the distance."

\section{Study Habits}

Participants mentioned that being distance learners encouraged them to improve their study habits. They mentioned spending more time reading the course materials and ensuring they comprehended the content before and after class. In some instances, this was primarily due to the fact that the audio from the class was not clear and thus prevented them from hearing the class discussion. In other instances, the participants felt that being proactive and reading the materials before class was important because it would allow them to ask questions during class time instead of having to email the instructors with a question. Overall, the participants felt that they were more 
accountable for their own learning and that they had to prove themselves to the instructors. For example, one participant (Ryan) explained, "I felt that every instructor had to see how good of a student I was and how well I could perform; so, I felt extra pressure to be in the top $10 \%$ of the class."

Several participants mentioned practicing better organization and time management skills to improve their study habits as well as being proactive to seek additional help (from classmates or instructor) when needed. One participant mentioned that being a distance learner encouraged her to improve her navigation skills in the learning management system so that she could access the asynchronous material available.

\section{Relationships and Communication with Classmates}

The next theme that emerged during the data analysis was a central component of the distance learners' experience in the hybrid synchronous classroom: the relationships and communication between distance learners and their face-to-face classmates. One participant (Ryan) mentioned that he has managed to maintain the relationships that had started in the classroom when he was a face-to-face learner. Ryan explained:

It was nice to have this connection because no one else in my personal network is in the instructional design field. Therefore, it is difficult for me to engage in discourse related to instructional design outside my peers in the classroom.

Another participant (Robin) mentioned that she had a strong intellectual and social connection with a face-to-face classmate and that had helped her tremendously as she transitioned to distance learning: "We [her close face-to-face classmate and her] talk every single semester and I am still good friends with her outside the classroom. I rely significantly on her because she is in all of my classes."

A point made by participants was that aside from those relationships created before they became distance learners, there was not much communication with their face-to-face classmates, unless they were working collaboratively on a team project. According to Katie, "It is almost like there is no discussion between the online people (the distance learners) and the students in the classroom." Ryan, on the other hand, commented, "The team for my project wanted to communicate synchronously, but they wanted to do it via video web. It actually ended being a benefit to us, we (the team) all ended up working remotely and being distance learners." Robin acknowledged that she communicated with her face-to-face classmates primarily during the inclass group assignments: "We had lots of group projects in class and group discussions, so for every single class I was with a different group via the iPad or in someone's computer screen via Google Hangouts.

\section{Hybrid Synchronous Instruction Technology}

Another central element that had an impact in the learning experience of the participants was the hybrid synchronous instruction classroom technology (hardware and software), in particular the Internet connection. According to Robin, "There were times I'd get kicked off the Internet connection and then I would miss class. I would have to contact someone in the class (a face-to-face learner) to inform them I was not online and was missing class." Katie mentioned a similar issue with the Internet connection:

Our university does not have the most up-to-date technology; therefore, there would be no Internet signal and I could not do any audio sharing. In some instances, I 
would have to call the classroom phone and the instructor would put me on speakerphone.

Another technology concern for the distance learners in the hybrid synchronous classroom was the quality of the audio to and from the face-to-face classroom. Ryan mentioned in his interview that is was difficult to understand the classroom discussion. He specified that "[Y]ou could always hear the professor very well but when it comes to the students responding, you'd usually hear this muffle in the background." Similarly, Robin stated that it was difficult to listen to the classroom discussion during the Google Hangouts sessions. Robin added that she would "call the instructor's phone and be on speakerphone to get a better classroom audio." Katie said the following about her experience with technology in the hybrid synchronous classroom: "I could mainly hear the instructor. The video and audio would freeze constantly. I would always have to re-learn what was lectured in the classroom after class and on my own."

Another issue indicated by the participants as part of their hybrid synchronous learning experience was the lack of technology that could help them see the notes and markings made by the instructor on the classroom whiteboards. Katie stated, "I cannot see the drawings the professors make in the board to demonstrate different points."

\section{Inequality in the Classroom}

Feelings of inequality were very common throughout the learning experience of these distance learners taking classes in the hybrid synchronous classroom. In some occasions, when working in group projects, the distance learners felt they were not treated equally by their group members, and that their opinion was not valued as much. For example, during the focus group, Ryan and Katie explained that there were occasions when their face-to-face group members would assign them the work to do for a project without asking for their preferences.

Another element of the learning experience that made the distance learners feel unequal compared to their face-to-face classmates was the layout of the software that was used for video sharing. During the class time, the instructors would primarily share their presentation slides with the class and the distance learners; therefore, the students in the two different formats (distance and face-to-face) could not see each other. This, in turn, made the distance learners feel as if they were "out of sight, out of mind."

Robin felt that her sense of inequality was primarily due to the fact that she was missing many of the social cues from her classmates, which are important during classroom discussion. She felt self-conscious when participating in class discussion. In her opinion, "When I participate through the classroom speakers, I feel that my voice just projects and everybody just stops or thinks it is funny. I want to be considered an equal participant in class."

As previously discussed, the distance learners also felt that they missed the ability to network and create relationships with their face-to-face classmates, which created a sense of inequality in the classroom. According to Katie, "It seems like everyone has a relationship with one another because they talk before, during, or after class. I miss the sense of being a part of the class or making friendships/connections."

\section{Relationship and Communication with Instructors}

An additional component of the experience of the distance learners in the hybrid synchronous classroom, and a theme from the data collected, was their relationship and communication with their instructor. Although initially the students felt like they were a burden to 
the instructor(s), the distance learners realized that their instructors were glad to help them with questions, concerns, or any additional information. Additionally, the distance learners stated that they were also more proactive about emailing the instructors, if needed, and the instructors (for the most part) would communicate with the distance learners in a timely manner. Robin mentioned that she preferred scheduling individual meetings with the instructor(s) via phone or Google Hangouts because she felt email could, at times, lead to misinterpretation.

In some instances, the distance learners resented the fact that technology issues would frequently cause them to miss important information that the instructor would pass on to students before, during, or at the end of a class session.

\section{Participating in Class}

One of the main themes that emerged in the data analysis was related to class participation. According to the distance learners, there were two important issues with class participation in the hybrid synchronous classroom. The first was the difficulty obtaining non-verbal cues from both the face-to-face learners and the distance learners. Such non-verbal cues help provide information on when to participate in class discussion. Since the distance learners did not have a video feed of the classroom and could not see their classmates, it was difficult for them to know when to participate in the discussion. Robin explained that she felt awkward interrupting her classmates when she tried to join the class discussion (and was unable to see the non-verbal cues). Ryan mentioned that not knowing when to cue in was one of the biggest challenges for him, because he was not visually aware of what was happening in the classroom. On the other hand, Ryan also stated that the lack of non-verbal cues (from his classmates) allowed him to give more truthful responses. According to Ryan: "You can be a lot more honest when you are at a distance."

The second issue mentioned significantly by the distance learners when it came to participating in the hybrid synchronous classroom was the difficulty hearing the audio. As mentioned in a previous theme (hybrid synchronous instruction technology), it was challenging for the distance learners to hear the class discussion and as Ryan explained: "It made it difficult to know what to contribute, when to contribute, and who was listening." It was also challenging for the distance learners to participate in the class discussion because the audio connection would drop during the transmission. Consequently, as the distance learners would share a comment with the class, the transmission would stop and the comment would be incomplete. This was extremely frustrating for the distance learners.

\section{Class Materials and Educational Tools}

Another theme that surfaced during the data analysis was the accessibility of class materials and the increased use of educational technology tools by the distance learners to enhance their learning experience. All three participants mentioned that the class materials were easily accessible to them because instructors would make materials available online either using the learning management system provided by the university or some other online platform (such as a Google+ Community). Ryan, Robin, and Katie also mentioned that due to their distance learning experience, they started to use more educational technology tools for content creation and storage (e.g. Dropbox and Google Drive), and screen sharing software and video conferencing tools (such as Google Hangouts, Skype, Adobe Connect). These educational technology tools helped them work in team projects synchronously/asynchronously, organize files and documents, create/share content with others, and communicate with face-to-face classmates while being at a distance. 


\section{Suggestions}

A significant portion of the data collected from the interviews, the focus group, and the electronic journal entries included suggestions that the participants provided for the improvement of the hybrid synchronous classroom at this specific institution. One of the main suggestions was related to the implementation of hardware that can help with the audio issues, such as the use of USB microphones in the classroom. Other suggestions involved using hardware and software to offer an equal environment for all students in the hybrid synchronous classroom. For example, Ryan recommended that the hybrid synchronous classroom should have computers (desktops or laptops) with access to a virtual classroom environment like Adobe Connect, where face-to-face and distance learners would be able to communicate during the class session.

Other suggestions were related to the wireless Internet connection. Robin explained that it is important for the institution to ensure a good wireless connection for the distance learners. One last suggestion to improve the hybrid synchronous classroom was the implementation of a SmartBoard that would allow the distance learners to see the drawings, markings, and/or notes made by the instructor in the whiteboard.

\section{Effectiveness of Program}

The most important element from the learning experience for the distance learners was the effectiveness of the program (using the hybrid synchronous instruction format) and their level of confidence on the knowledge acquired. All participants stated that they believed that the program had prepared them for their career as instructional designers. Robin announced that she was already working as an instructional designer, having received a job offer at the beginning of her last semester in the program. Robin shared, "I currently work as an instructional designer, so I have benefitted from the program already." With regards to the program, Ryan commented, "It was nice to finally learn about learning, and not to learn about learning from a teaching perspective, but more from a design perspective." Lastly, Katie mentioned that the program had provided her with "direction for a tangible career as an instructional designer."

Additionally, two of the participants expressed that they feel confident about the instructional design knowledge acquired during their studies in the program. Ryan mentioned that progressing through the program part-time really helped him gain a good understanding of all the principles and the different theories and their application. Katie expressed that progressing through the program as a distance learner was where she found her strength. She added that she used her distance learning experience in the hybrid synchronous classroom and turned it into an advantage for her and her studies: "I feel like I have a better grasp on the relationship between technology and learning."

\section{Discussion}

The themes which emerged from the data collected during the case study demonstrate that during hybrid synchronous instruction, from the distance learners' perspective, the following elements were a significant part of the overall learning experience:

A. Need for Stronger Connection with Classmates: The three distance learners expressed enjoyment when working together with other classmates, particularly with others at a distance. Instances in which participants had the chance to work with other learners in the same situation made them feel more integrated to that community of practice. Additionally, the strongest bond 
between the distance learners and face-to-face learners occurred in situations when they had met face-to-face, which allowed them to maintain that connection throughout the remainder of the program. New connections were not established between distance and face-to-face learners, which aided in the feeling of inequality in classroom activities.

B. Improvement in Study Habits: The technical issues that often prevented the distance learners from hearing the instructor or participating in all class discussions contributed to a higher accountability of the three participants, some of whom felt the need to prove themselves to the instructors. Such attitude and desire to increase their understanding on the subject transformed their study habits from passive to more proactive, which improved their time management and organizational skills. Learning at a distance allowed for the use of educational technology tools to be greatly improved during the program, especially when it came to interacting with other classmates and cooperating in an online environment.

C. Challenges in Classroom Participation: Even though all distance learners in this case study made every effort to contribute to class discussions, technical issues many times prevented them from doing so. Not knowing when to cue in, and a feeling of embarrassment and discomfort to ask for repetition due to having missed key information created the greatest differences between the distance learners' and the face-to-face learners' experience in the hybrid synchronous classroom.

D. Level of Confidence in their Knowledge: All distance learners demonstrated having a higher level of confidence at the end of the program, in particular due to the challenges they faced, which allowed them to become better professionals in the field of instructional design and technology. The hybrid synchronous instruction format of the courses also allowed distance learners to immediately put theory into practice, which in some cases does not happen in the faceto-face setting.

\section{Implications for Practice}

There are several benefits that come from the integration of distance and face-to-face learners in a hybrid synchronous classroom. It enables access to students who are geographically isolated or cannot physically attend classes due to life demands (Bower et al., 2013; Chakraborty \& Victor, 2004; Hastie et al., 2010). It also reduces the cost of additional on-campus infrastructure and brick-and-mortar classrooms. Furthermore, it provides an alternative for those students who do not want to enroll in a fully online program (Bell et al., 2014). Today, there are also a wide variety of tools used to facilitate hybrid synchronous instruction (Bell et al., 2014; Bower et al., 2013); video conferencing software, screen sharing software, and synchronous document editing software are just a few of them (Chakraborty \& Victor, 2004).

The results of this case study reveal that certain challenges can prevent the distance learners from having the same learning experience as their face-to-face counterparts in the hybrid synchronous classroom. These challenges require careful consideration by instructors, administrators, and institutions who desire to adopt hybrid synchronous instruction. Understanding that there are certain interactions, relationships, and communication exchanges that do not occur as naturally when students are not sharing the same physical space, instructors and instructional designers need to create learning experiences that facilitate opportunities for exchanges which enhance interactions, relationships, and communication between distance learners and face-to-face learners in the same hybrid synchronous instructional environment. 
The challenges faced by the distance learners in the case study demonstrate the need for adequate infrastructure (microphones, speakers, and adequate wireless Internet) to help establish the interactions, communication, and sense of equality between all learners in the hybrid synchronous classroom. We also learned that it is key for instructors to be pro-active in their instruction, to maintain open communication channels with all students, to make materials available in advance, and to ensure that activities during hybrid synchronous sessions allow all students to be part of the class. Last, the analysis of the case study indicates that it is important for distance learners in hybrid synchronous environments to stay motivated and accountable throughout the instruction. It will help them maintain adequate study habits and increase the overall effectiveness of the instruction.

\section{Conclusion}

This case study contributes to the literature regarding the effectiveness and efficiency of hybrid synchronous instruction. It provides helpful data regarding the experience of distance learners in this setting to inform instructors/instructional designers who wish to implement synchronous online instruction. Sharing this case study with the larger community of researchers on online and distance learning could encourage others to further explore this promising instructional format, as the results reinforce that hybrid synchronous instruction holds much promise as an alternative to the two more traditional formats, fully online or face-to-face. 


\section{References}

Bell, J., Sawaya, S., \& Cain, W. (2014). Synchromodal classes: designing for shared learning experiences between face to face and online students. International Journal of Designs for Learning, 5(1).

Bonakdarian, E., Whittaker, T., \& Yang, Y. (2010). Mixing it up: more experiments in hybrid learning. Journal of Computing Sciences in College, 25(4), 97-103.

Bower, M., Dalgarno, B., Kennedy, G. E., Lee, M. J. W., \& Kenney, J. (2015). Design and implementation factors in blended synchronous learning environments: Outcomes from a cross-case analysis. Computers \& Education, 86, 1-17. doi: http://dx.doi.org/10.1016/j.compedu.2015.03.006

Bower, M., Kenney, J., Dalgarno, B., Lee, M. J. W., \& Kennedy, G. E. (2013, 2013). Blended synchronous learning : patterns and principles for simultaneously engaging co-located and distributed learners. Paper presented at the Electric Dreams: Australasian Society for Computers in Learning in Tertiary Education, Sydney, Australia.

Butz, N. T., Stupnisky, R. H., Peterson, E. S., \& Majerus, M. M. (2014). Motivation in synchronous hybrid graduate business programs: A self-determination approach to contrasting online and on-campus students. [Article]. MERLOT Journal of Online Learning \& Teaching, 10(2), 211-227.

Chakraborty, M., \& Victor, S. (2004). Do's and don'ts of simultaneous instruction to on-campus and distance students via videoconferencing. Journal of Library Administration, 41(1-2), 97-112. doi: 10.1300/J111v41n01_09

Creswell, J. W. (2009). Research design Qualitative, Quantitative, and Mixed Methods Approaches (Third Edition ed.). Los Angeles, CA: Sage.

Cunningham, U. (2014). Teaching the disembodied: Othering and activity systems in a blended synchronous learning situation. The International Review of Research in Open and Distance Learning, 15(6).

Hastie, M., Hung, I. C., Chen, N. S., \& Kinshuk. (2010). A blended synchronous learning model for educational international collaboration. Innovations in Education and Teaching International, 47(1), 9-24. doi: 10.1080/14703290903525812

Lee, R., \& Dashew, B. (2011). Designed learner interactions in blended course delivery. Journal of Asynchronous Learning Networks, 15(1), 68-76.

McGee, P., \& Reis, A. (2012). Blended course design: A synthesis of best practices. Journal of Asynchronous Learning Networks, 16(4), 7-22.

Niemiec, M., \& Otte, G. (2009). An administrator's guide to the whys and hows of blended learning. Journal of Asynchronous Learning Networks, 13(1), 19-30.

Oyarzun, B., \& Martin, F. (2013). A case study on multi-modal course delivery and social learning opportunities. Bulleting of the IEEE Technical Committee on Learning Technology, 15(1), 25-28. 
Park, Y., \& Bonk, C. J. (2007). Is online life a breeze? A case study for promoting synchronous learning in a blended graduate course. MERLOT Journal of Online Learning and Teaching, 3(3).

Patton, M. Q. (2015). Qualitative Research and Evaluation Methods (Fourth Edition ed.). Thousand Oaks, CA: SAGE Publications.

Plummer, K. (2001). The call of life stories in ethnographic research. In P. Atkinson, A. Coffey, S. Delamont, J. Lofland \& L. Lofland (Eds.), Handbook of Ethnography: SAGE Publications.

Popov, O. (2009). Teachers' and students' experiences of simultaneous teaching in an international distance and on-campus master's programme in engineering. The International Review of Research in Open and Distance Learning, 10(3).

Rogers, P. C., Graham, C. R., Rasmussen, R., Campbell, J. O., \& Ure, D. M. (2003). CASE 2 Blending face-to-face and distance learners in a synchronous class: Instructor and learner experiences. [Article]. Quarterly Review of Distance Education, 4(3), 245-251.

Roseth, C., Akcaoglu, M., \& Zellner, A. (2013). Blending synchronous face-to-face and computer-supported cooperative learning in a hybrid doctoral seminar. TechTrends, 57(3), 54-59. doi: 10.1007/s11528-013-0663-z

Stewart, A. R., Harlow, D. B., \& DeBacco, K. (2011). Students' experience of synchronous learning in distributed environments. Distance Education, 32(3), 357-381. doi: 10.1080/01587919.2011.610289

Szeto, E. (2015). Community of Inquiry as an instructional approach: What effects of teaching, social and cognitive presences are there in blended synchronous learning and teaching? Computers \& Education, 81, 191-201. doi: http://dx.doi.org/10.1016/j.compedu.2014.10.015

White, C. P., Ramirez, R., Smith, J. G., \& Plonowski, L. (2010). Simultaneous delivery of a faceto-face course to on-campus and remote off-campus students. TechTrends, 54(4), 34-40. doi: $10.1007 / \mathrm{s} 11528-010-0418-\mathrm{z}$

Yin, R. (2014). Case Study Research: Design and Methods (Aplied Social Research Methods). Thousand Oaks, CA: SAGE Publications. 


\section{Appendix A}

\section{Individual Interview and Focus Group Protocol}

The purpose of this individual interview [focus group] is to discuss your experiences as distance learners in a predominantly face-to-face classroom. Thank you for agreeing to speak with me today. This focus group will last approximately 45 minutes and will consist of several questions.

As we discussed previously, this conversation will be digitally recorded. Do you still provide your consent to have this interview recorded?

This study is part of research investigation and the information you provide will be held in complete confidentiality. No information you present to me will be linked back to you in any way. If at any time during the interview you feel uncomfortable, you have the right to stop the interview and withdraw from the study. Do you have any questions?

Thank you again for your participation, are you ready to begin?

1. What was your experience with in-classroom collaborative assignments as a distance learner in a predominantly face-to-face classroom?

2. What was your experience with access to class materials as a distance learner in a predominantly face-to-face classroom?

3. What was your experience with participation during class discussion as a distance learner in a predominantly face-to-face classroom?

4. Where there any educational technology tools that assisted you during your class sessions as a distance learner?

5. What challenges did you face during your distance learning experience related to technology issues (internet, audio, presentations)? How did you overcome these challenges?

6. Do you have any additional comments? 